\title{
The influence of street layouts and viaduct settings on daily carbon monoxide exposure and intake fraction in idealized urban canyons
}

Article

Accepted Version

Creative Commons: Attribution-Noncommercial-No Derivative Works 4.0

Hang, J., Luo, Z., Wang, X., He, L., Wang, B. and Zhu, W. (2017) The influence of street layouts and viaduct settings on daily carbon monoxide exposure and intake fraction in idealized urban canyons. Environmental Pollution, 220 (Part A). pp. 72-86. ISSN 0269-7491 doi: https://doi.org/10.1016/j.envpol.2016.09.024 Available at https://centaur.reading.ac.uk/66739/

It is advisable to refer to the publisher's version if you intend to cite from the work. See Guidance on citing.

To link to this article DOI: http://dx.doi.org/10.1016/j.envpol.2016.09.024

Publisher: Elsevier

All outputs in CentAUR are protected by Intellectual Property Rights law, including copyright law. Copyright and IPR is retained by the creators or other copyright holders. Terms and conditions for use of this material are defined in the End User Agreement. 


\section{www.reading.ac.uk/centaur}

\section{CentAUR}

Central Archive at the University of Reading

Reading's research outputs online 


\section{$\underline{\text { Revision to Environmental Pollution } 2016}$}

\section{The influence of street layouts and viaduct settings on daily carbon monoxide} exposure and intake fraction in idealized urban canyons

\section{Jian Hang ${ }^{1}$, Zhiwen Luo ${ }^{2 *}$, Xuemei Wang ${ }^{1}$, Lejian He ${ }^{1}$, Baomin Wang ${ }^{1}$, Wei Zhu ${ }^{1}$}

${ }^{1}$ School of Atmospheric Sciences, Sun Yat-sen University, Guangzhou, P.R. China ${ }^{2}$ School of the Built Environment, University of Reading, Reading, UK

*Corresponding author. Zhiwen Luo

Tel: $+44(0) 1183785219$ fax: +44(0) 1183785219

E-mail address: z.luo@ reading.ac.uk

\section{ABSTRACT}

Environmental concerns have been raised on the adverse health effects of vehicle emissions in micro-scale traffic-crowded street canyons, especially for pedestrians and residents living in near-road buildings. Viaduct design is sometimes used to improve transportation efficiency but possibly affects urban airflow and the resultant exposure risk, which have been rarely investigated so far. The personal intake fraction $\left(P_{-} I F\right)$ is defined as the average fraction of total emissions that is inhaled by each person of a population $\left(1 \mathrm{ppm}=1 \times 10^{-6}\right)$, and the daily carbon monoxide (CO ) pollutant exposure $\left(E_{\mathrm{t}}\right)$ is estimated by multiplying the average concentration of a specific micro-environment within one day. As a novelty, by considering time activity patterns and breathing rates in various micro-environments for three age groups, this paper introduces $I F$ and $E_{\mathrm{t}}$ into computational fluid dynamic (CFD) simulation to quantify the impacts of street layouts (street width/ building height $W / H=1,1.5,2$ ), source location, viaduct settings and noise barriers on the source-exposure correlation when realistic $\mathrm{CO}$ sources are defined. Narrower streets experience larger $\mathrm{P} \_I F$ (1.51-5.21 ppm) and CO exposure, and leeward-side buildings always attain higher 
vehicular pollutant exposure than windward-side. Cases with a viaduct experience smaller $P \_I F(3.25-1.46 \mathrm{ppm})$ than cases without a viaduct $\left(P \_I F=5.21-2.23 \mathrm{ppm}\right)$ if the single ground-level $\mathrm{CO}$ source is elevated onto the viaduct. With two $\mathrm{CO}$ sources (both ground-level and viaduct-level), daily $\mathrm{CO}$ exposure rises 2.80-3.33 times but $P \_I F$ only change slightly. Noise barriers above a viaduct raise concentration between barriers, but slightly reduce vehicular exposure in near-road buildings. Because people spend most of their time indoors, vehicular pollutant exposure within near-road buildings can be 6-9 times that at pedestrian level. Although further studies are still required to provide practical guidelines, this paper provides effective methodologies to quantify the impacts of street/viaduct configurations on human exposure for urban design purpose.

\section{*Capsule (Limit 185 Characters)}

Wider street and urban viaduct with a single elevated source could alleviate indoor exposure and building intake fraction. Adding noise barriers has no significant impact.

Keywords: Street canyon, Intake fraction, Daily pollutant exposure, Viaduct, Noise barrier

\section{Introduction}

Following the ongoing worldwide urbanization, traffic exhaust and non-exhaust emissions in cities constitute the major sources of urban air pollution, including fine particulate matter $\left(\mathrm{PM}_{2.5}\right)$, carbon monoxide, nitric oxide and benzene etc (Fenger, 1999; Pu and Yang, 2014 ).The population exposure to high air pollutant concentration is one of the major factors resulting in adverse health problems in cities (Luo et al., 2010; Zhou et al., 2013; Ji and Zhao, 2015), especially for sensitive groups like children and the elderly. Moreover, on average people spend more than $90 \%$ of their time indoors, the traditional epidemiology study linking mortality directly to outdoor pollution concentration may cause bias and give rise to exposure misclassification (Chen et al., 2012a,b) as outdoor air pollutants could penetrate 
indoors via doors/windows, ventilation systems and building cracks and cause indoor exposure to outdoor origins (Chen et al., 2012c; Ji and Zhao, 2015). Thus, improving the dispersion of vehicular pollutants in the urban environment can help improving urban air quality and reducing population exposure for both pedestrians and people living in near-road buildings (Zhang and Gu, 2013; Ng and Chau, 2014).

Extremely narrow street configurations, heavy traffic volumes and unfavourable meteorological conditions are the main reasons of serious vehicular street air pollution. As recently reviewed by the literature (Fernando et al., 2010; Kumar et al., 2011; Di Sabatino et al., 2013; Blocken, 2015; Meroney et al., 2016; Lateb et al., 2016), numerous field/wind tunnel experiments and computational fluid dynamic (CFD) simulations have contributed to understanding the impacts of urban design on the flow and urban air pollution. It has been widely confirmed as the most effective design approach to improve street pollutant dispersion by lowering street aspect ratios (street height/street width, $H / W$ ) in two-dimensional (2D) street canyons (Oke, 1988; Meroney et al., 1996; Vardoulakis et al., 2003; Li et al., 2006; Xie et al., 2006; Li et al., 2009; Liu and Wong, 2014; Zhong et al., 2015) and building packing densities in three-dimensional (3D) urban-like models (Chang and Meroney, 2003; Di Sabatino et al., 2007; Hang and Li, 2011; Buccolieri et al., 2010; Yang et al., 2013; Ramponi et al., 2015). Other key urban parameters include building height variations (Gu et al., 2011; Hang et al., 2012) and typical high-rise buildings (Zhang et al., 2015), ambient wind directions (Kanda, 2006; Yassin, 2013; Lin et al., 2014; Kwak et al., 2016), street vegetation (Buccolieri et al., 2011; Gromke and Blocken, 2015a and 2015b), building roof shape (Takano and Moonen, 2013; Liu et al., 2015), traffic-flow patterns (Thaker and Gokhale, 2016) and real-time boundary wind conditions (Zhang et al., 2011) etc. In addition, thermal buoyancy forces induced by wall heating and solar shading can significantly influence (Cai, 2012; Allegrini et al., 2014; Yang and Li, 2015; Cui et al., 2016; Nazarian and Kleissl, 2016) or dominate (Yang and Li, 2009; Luo and Li, 2011; Dallman et al., 2014; Wang and Li, 2016) urban airflows and pollutant dispersion if Richardson (Froude) number is relatively large (small), 
special concern (Zhou and Levy, 2008; Ng and Chau, 2014; Habilomatis and Chaloulakou, 2015) where the health risk is much higher than in other microenvironments. Most studies investigated the wind flow and emphasized spatial distribution of pollutant concentration in street canyons (e.g. Meroney et al., 1996; Xie et al., 2006; Li et al., 2009; Zhong et al., 2015) or near-road buildings (Kalaiarasan et al., 2009; Quang et al., 2012). However, the resultant pollutant exposure averaged over the population in the entire street canyon is more important for evaluating the overall impacts on people's health. Vehicular pollutant exposure is determined by three factors: the pollutant emission rate (mass per unit time) depending on traffic density, the capacity of pollutant dispersion associated with urban layouts and meteorological conditions, the distance of people from pollutant sources and time activity patterns. Furthermore, viaducts are sometimes used to improve transportation efficiency in traffic-crowded urban areas. Noise barriers at two sides of a viaduct are usually adopted to protect near-road residents from the adverse effects of noise, but possibly influence pollutant exposure. To date, there remains a shortage of studies reporting on how street layouts coupled with viaduct settings and noise barriers influence pollutant exposure in near-road buildings.

The concept of intake fraction $(I F)$ represents the fraction of total pollutant emissions that is inhaled by a population (Bennett et al., 2002). Only a few studies estimated IF within micro-scale urban canyons (Zhou and Levy, 2008; Habilomatis and Chaloulakou, 2015). But the existing studies only considered realistic streets as case studies and did not examine how IF would be affected by street layouts and viaduct settings for design purpose. By conducting CFD simulations coupling with daily pollutant exposure, $\mathrm{Ng}$ and Chau (2014) assessed how the designs of building permeability and street setbacks influence daily population exposure inside idealized street canyons, but they did not look at the interactive flow between urban space and interior building space. As a novelty, this paper introduces two metrics, i.e., both intake fraction $(I F)$ and daily pollutant exposure into CFD simulations to quantify the impacts of street aspect ratios, viaduct settings, noise barriers and source locations on vehicular exposure under neutral meteorological conditions, for street and viaduct 
design purpose.

The remainder of this paper is structured as follows: Section 2 describes the concepts of personal intake fraction $\left(P_{-} I F\right)$ and daily pollutant exposure. Section 3 introduces CFD setups and test cases investigated, while Section 4 presents CFD validation using wind tunnel data. Results are discussed in Section 5 and conclusions are drawn in Section 6.

\section{Human exposure indices to vehicle emissions}

\subsection{Personal intake fraction $\left(P_{-} I F\right)$}

An intake fraction $(I F)$ of $1 \mathrm{ppm}$ (part per million) indicates that $1 \mathrm{~g}$ of air pollutants is inhaled by an exposed population from one ton of pollutants emitted from the source. Obviously $I F$ depends on population density, but is independent of the pollutant release rate. $I F$ has been widely used to determine the fraction of total emissions that is inhaled by a population at various scales. Indoor $I F$ is commonly high $\left(\sim 2-20 \times 10^{3} \mathrm{ppm}\right)$ (Nazaroff, 2008) due to human's close proximity to pollutant sources. City-scale and regional-scale vehicular $I F$ are relatively small, for example, IF of 1-10 ppm in US cities (Marshall et al., 2005) and 270 ppm in Hong Kong (Luo et al., 2010), and $I F$ of primary $\mathrm{PM}_{2.5}$ for the entire continental United States was reported at 0.12-25 ppm (Greco et al., 2007).

The high-resolution vehicular $I F$ in micro-scale street canyons should be further emphasized. So far, only a few researchers examined street-scale $I F$ for case studies. Recently, Habilomatis and Chaloulakou (2015) conducted CFD simulations to calculate $I F$ of vehicular ultrafine particles in a 2D street canyon $(H / W=1.5)$ of the central Athens in Greece reporting an overall $I F$ of $371 \mathrm{ppm}$. By using modelling data (not CFD), Zhou and Levy (2008) investigated IF for a typical street canyon in midtown Manhattan, New York, obtaining an overall $I F$ of 3000 ppm due to the high population density and poor urban ventilation. This paper aims to examine how idealized street layouts and viaduct settings affect vehicular pollutant distribution and its resultant exposure to inform future urban design.

For a specific vehicular pollutant, the intake fraction $(I F)$ is defined as below 
$I F=\sum_{i}^{N} \sum_{j}^{M} P_{i} \times B r_{i, j} \times \Delta t_{i, j} \times C e_{j} / m$

153

where $m$ is the total emission rate over the period considered $(\mathrm{kg}), N$ is the number of population groups defined and $M$ is the number of different microenvironments considered, $P_{i}$ is the total number of people exposed in the $i^{\text {th }}$ population group; $B r_{i j}$ is the average volumetric breathing rate for individuals in the $i^{\text {th }}$ population group $\left(\mathrm{m}^{3} / \mathrm{s}\right)$ in the microenvironment $j ; \triangle t_{i j}$ is the time spent in the microenvironment $j$ for people group of $i(\mathrm{~s})$; and $C e_{j}$ is the pollutant concentration attributable to traffic emissions in the microenvironment $j\left(\mathrm{~kg} / \mathrm{m}^{3}\right)$.

As referred to the literature (Chau et al., 2002; Allan et al., 2008), breathing rates in four micro-environmental categories $(M=4)$ for three age groups $(N=3)$ were defined (Fig. A1a in Appendix): indoors at home $(j=1)$, other indoor locations $(j=2)$, near vehicles $(j=3)$, and other outdoor locations away from vehicles $(j=M=4)$. The 2004 population census data for the Hong Kong (Luo et al., 2010) were adopted (Fig. A1b). Moreover, some assumptions were further proposed: The near-road buildings were residential, and only $j=1$ (Indoors at home) and $j=3$ (near vehicles, i.e. pedestrian level) were considered to assess $I F$ for local residents and pedestrians (Fig. A1a).

Because $I F$ for the entire population rises linearly with the increasing population density, this paper proposes the average personal intake fraction $\left(P_{-} I F\right)$ for a virtual person. This virtual person has an average breathing rate $T B r_{j}$ combining the population subgroups for each time-activity pattern $j(j=1$ and 3$)$. Thus $P \_I F$ is independent of population density.

$$
P_{-} I F=I F / \sum_{i}^{N} P_{i}=\sum_{j}^{M} T B r_{j} \times \Delta t_{j} \times C e_{j} / m
$$

Here $\triangle t_{j}$ is the time spent in the microenvironment $j$ for the entire population.

\subsection{Daily Pollutant exposure of $\mathrm{CO}\left(\mathrm{E}_{t}\right)$}

The daily pollutant exposure is defined as the extent of human beings' contact 
with different air pollutants within one day which is estimated indirectly by multiplying the average concentration of a specific micro-environment within the time people spend in it. Different from the intake fraction, daily pollutant exposure depends on the realistic pollutant emission rates. Mathematically, for a specific population subgroup, it is calculated as below (Ng and Chau, 2014):

$$
E_{t}=\sum_{j=1}^{M} E_{t, j}=\sum_{j=1}^{M} C_{r e a l, j, k} \times t_{j}
$$

where $E_{t, \mathrm{j}}$ is the daily pollutant exposure $\left(\mathrm{mg} / \mathrm{m}^{3} /\right.$ day) of the $j^{\text {th }}$ microenvironment, and $j=1,2,3,4$ representing the time activity pattern in Fig. A1 a. Thus, $E_{t}$ is the total pollutant exposure for all microenvironments. $C_{\text {real }, j, k}$ is the exposed pollutant concentration in the $j^{\text {th }}$ microenvironment at the $k^{\text {th }}$ side (leeward or windward side). Similarly, we only considered the time $t_{\mathrm{j}}$ people spend indoors at home $(j=1)$ or near vehicles $(j=3)$ within a day (Fig. A1a) assuming near-road buildings are residential.

\section{CFD methodologies}

\subsection{Description of CFD test cases and flow modelling}

Large Eddy Simulations (LES) are known to perform better in predicting turbulence than the Reynolds-Averaged Navier-Stokes (RANS) approaches in urban airflows and pollutant dispersion modelling (Kanda, 2006; Gu et al., 2011; Li et al., 2009 and 2015; Liu et al., 2014 and 2015; Zhong et al., 2015). But there are still challenges to LES applications including the much longer computational time, the development of advanced sub-grid scale models, the difficulty in specifying appropriate time-dependent inlet and wall boundary conditions. We are aware that steady RANS turbulence models have deficiencies in predicting turbulence, for example they fail to predict the sizes of reattachment lengths behind buildings and under-predict the velocity in weak wind regions (Yoshie et al., 2007). In spite of its limitations, the RNG $k-\varepsilon$ model (Yakhot and Orszag, 1986) has been successfully validated in predicting mean airflows and pollutant dispersion in urban-like models (e.g.Tominaga and Stathopoulos, 2013; Ho et al., 2015; Blocken, 2015; Meroney, 2016; Habilomatis and Chaloulakou, 2015) and those coupling indoor-outdoor airflows (e.g. Gao et al., 
2008; van Hooff and Blocken, 2010 and 2013; Ramponi and Blocken, 2012; Jin et al., 2015; Hang et al., 2016). Thus CFD software Ansys FLUENT (Fluent, 2006) with the RNG $k-\varepsilon$ model was used to solve the steady-state isothermal urban airflows. The governing equations were discretized by a finite volume method with the second order upwind scheme. The SIMPLE scheme was used for the pressure and velocity coupling.

Fig. 1 depicts full-scale urban models investigated by CFD simulations. The height of all buildings stays as constant as $H=24 \mathrm{~m}$ ( $y$ direction), and the width of target street canyon varies from $W=24,36$ to $48 \mathrm{~m}(W / H=1,1.5,2)$ with its span-wise (or lateral) length of $L=12 \mathrm{~m}$ ( $y$ direction). There are two identical street canyons $\left(W^{\prime}=24 \mathrm{~m}\right)$ neighbour to the target street canyon with one in the upstream and the other in the downstream to explicitly reproduce roughness elements. There are eight-storey buildings at both leeward and windward sides with a door at the first floor ( $2 \mathrm{~m}$ tall, $4 \mathrm{~m}$ wide) and windows ( $1 \mathrm{~m}$ tall, $4 \mathrm{~m}$ wide) at the other storeys. Each storey is $3 \mathrm{~m}$ high with the room height of $2.7 \mathrm{~m}$ and room floor thickness of $0.3 \mathrm{~m}$. For cases with a viaduct, the width of the viaduct is fixed as $W_{\mathrm{b}}=16 \mathrm{~m}$. The viaduct is elevated as $9 \mathrm{~m}$ above the ground, and its thickness is $1 \mathrm{~m}$. In addition, there are noise barriers installed at the sides of the viaduct. Two barrier heights are considered, i.e., $2 \mathrm{~m}$ and $4 \mathrm{~m}$ respectively. The birds' eye view in cases with a viaduct are depicted in Fig. A2. The model description in test cases without a viaduct is also displayed in Fig. 1. At two lateral domain boundaries, symmetrical boundary conditions are assumed. We are aware that, an idealized 2D street canyon with symmetrical lateral boundary condition represents a simplified urban geometry of an infinitely long street with a perpendicular approaching wind to street axis, but it can serve as a platform to synthesize the physical and chemical processes found in the urban environment which is currently still and commonly investigated (Allegrini et al., 2014; Ho et al., 2015; Liu et al., 2014 and 2015; Li et al., 2015; Zhong et al., 2015). The similar 2D urban model coupling indoor and outdoor airflows have been adopted by Gao et al. (2008) and Hang et al. (2016).

All test cases are summarized in Table 1. Three kind of street canyons with $W / H$ 
$238=1,1.5$ or $2(H=24 \mathrm{~m})$ are included, and four types of viaduct settings are considered,

239 i.e. with no viaduct (Case $\mathrm{Nv}[W / H]$ ), with viaduct but no noise barriers (Case

$240 \mathrm{~V}[W / H])$, with viaduct and barrier 1 (2 m tall, Case Vb1[W/H]), with viaduct and

241 barrier 2 (4 $\mathrm{m}$ tall, Case $\mathrm{Vb} 2[W / H])$. The grid size normal to wall surfaces is $0.1 \mathrm{~m}$

$242(0.004 H)$ which is based on the grid independence study in the CFD validation case.

243 CFD grid arrangement in cases with a viaduct is depicted in Fig. A2. The total number

244 of hexahedral cells is about 1.3 million to 2.1 million. For Case Nv[1], we also used a

245 finer grid arrangement with grid size of $0.05 \mathrm{~m}$ at wall surfaces to perform a

246 mesh-dependency test, finding that CFD results change little with the finer grid.

247 No-slip wall boundary condition with standard wall function was applied for 248 near-wall treatment. Zero normal gradient conditions were used at the domain top (i.e. 249 symmetry), domain outlet (i.e. outflow) and two lateral domain boundaries (i.e. 250 symmetry). At the domain inlet, a power-law velocity profile was applied as below.

$$
U_{0}(z)=U_{r e f}\left(\frac{z-H}{z_{r e f}}\right)^{\alpha}
$$

$k_{\text {in }}(z)=\left(U_{\text {in }}(z) \times I_{\text {in }}\right)^{2}$

$\varepsilon_{i n}(z)=\frac{C_{\mu}^{3 / 4} k_{i}^{3 / 2}}{\kappa z}$

where $U_{\text {ref }}=3 \mathrm{~m} / \mathrm{s}$ is the reference velocity, $H=24 \mathrm{~m}$ and $z_{\text {ref }}$ is the reference height of $40 \mathrm{~m}$. The power-law exponent of $\alpha=0.22$ denotes the underlying surface roughness depending on the terrain category of a medium-dense urban area. $I_{\text {in }}=0.1$ is turbulence intensity, $C_{\mu}=0.09$ and $\kappa$ is the von Karman constant $(\kappa=0.41)$.

The reference Reynolds number based on the building height $\left(\operatorname{Re}=U_{r e f} H / v, v\right.$ is the kinematic viscosity, $H=24 \mathrm{~m}$ ) is about $4.8 \times 10^{6}$ and that based on the room window height is $19733\left(\operatorname{Re}=U_{r e f} h_{w} / v, h_{w}=0.1 \mathrm{~m}\right)$. Both are much greater than 11000 to ensure Reynolds number independence (Snyder, 1972).

\subsection{CFD setups in dispersion modelling}

In this study, carbon monoxide (CO) was selected as a vehicular pollutant being 
emitted from volumetric sources in the target street canyon. For cases with a viaduct (Fig. 1), there are two situations of CO sources: (1.) a single CO source (Source 1) is fixed above the viaduct (i.e. viaduct-level only, no source near the ground), (2.) two $\mathrm{CO}$ sources are present at viaduct-level (Source 1) and ground-level (Source 2, near the ground). The geometry sizes and emission rates of $\mathrm{CO}$ sources are fixed as constants (width $W_{\mathrm{b}}=16 \mathrm{~m}$, length $L=12 \mathrm{~m}$ ). $\mathrm{Ng}$ and Chau (2014) adopted a realistic total traffic emission of carbon monoxide $(\mathrm{CO})$ with the release rate of $6503.6(\mathrm{~g} / \mathrm{h})$ by counting traffic numbers in a realistic street (source length=street length $=180 \mathrm{~m}$ ) in Mongkok, Hong Kong, as proposed by Xia and Shao (2005). This paper utilizes the same emission rate per unit street length $(36.1 \mathrm{~g} / \mathrm{h} / \mathrm{m}$, source length $L=12 \mathrm{~m}$, Fig. 1) for each $\mathrm{CO}$ source. Obviously with two $\mathrm{CO}$ sources the total realistic $\mathrm{CO}$ emission rate doubles. For cases without a viaduct, only ground-level Source 2 exists within the pedestrian regions ( $z=0$ to $2 \mathrm{~m}$, Fig. 1 ).

The governing equation of time-averaged CO concentration $C\left(\mathrm{~kg} / \mathrm{m}^{3}\right)$ is:

$\bar{u}_{j} \frac{\partial C}{\partial x_{j}}-\frac{\partial}{\partial x_{j}}\left(\left(D_{m}+D_{t}\right) \frac{\partial C}{\partial x_{j}}\right)=S$

where $\bar{u}_{j}$ is the time-averaged velocity component, $S$ is the CO emission rate, $D_{m}$ and $D_{t}$ are the molecular and turbulent diffusivity of pollutants. Here $D_{t}=v_{t} / S c_{t}, v_{t}$ is the kinematic eddy viscosity and $S c_{t}$ is turbulent Schmidt number $\left(S c_{t}=0.7\right)$ (Hang et al., 2012; Di Sabatino et al., 2007).

For the boundary condition of Eq. (5), the zero normal flux condition was set at wall surfaces, and zero normal gradient conditions at the domain outlet and domain roof. At the domain inlet, the concentration was defined as zero. It is worth mentioning that, in present CFD simulations, the density of air is $1.177 \mathrm{~kg} / \mathrm{m}^{3}$ (average molecular weight 28.966) which is a little greater than the density of CO density difference is little. 
After Eq. (5) was solved, the personal intake fraction and daily $\mathrm{CO}$ exposure were analysed. Here we mainly considered two microenvironments (Fig. A1a), in near-road buildings (indoors at home) and for pedestrian regions (near vehicles).

\section{CFD validation studies}

\subsection{CFD Validation of single-sided ventilation flow modelling}

Wind tunnel data from the literature (Jiang et al., 2003) were used to evaluate the numerical accuracy of isothermal flows in single-sided ventilation by coupling indoor and outdoor airflows. As depicted in Fig. A3, the dimension of the reduced-scale cubic building is $0.25 \mathrm{~m} \times 0.25 \mathrm{~m} \times 0.25 \mathrm{~m}$, with a wall thickness of $0.006 \mathrm{~m}$ and opening size of $0.125 \mathrm{~m} \times 0.084 \mathrm{~m}$ at both windward-side or leeward-side walls. The time-averaged stream-wise velocity $U$ and vertical velocity $V$ along 10 vertical lines at the building centre section were measured by a laser Doppler anemometer (Jiang et al., 2003). In CFD simulations (Fig. A3a), full-scale models with a building size of $2.5 \mathrm{~m} \times 2.5 \mathrm{~m} \times 2.5 \mathrm{~m}$ and opening size of $1.25 \mathrm{~m} \times 0.84 \mathrm{~m}$ were used (scale ratio is $10: 1) . x$, $y$ and $z$ are the stream-wise, span-wise (lateral) and vertical directions. $x / H=0$ is the location of the windward building surface. The computational domain has a downstream length of $28 \mathrm{H}$, an upstream length of $6 \mathrm{H}$, a lateral length of $7.5 \mathrm{H}$ on both sides, and a height of $6 H$.

At the domain inlet, the vertical profiles of stream-wise velocity $U_{0}(z)$, turbulent

where $u *$ is the friction velocity which equals $1.068 \mathrm{~m} / \mathrm{s}, z_{0}$ is the aerodynamic roughness height equalling $0.05 \mathrm{~m}$ in the full-scale CFD model.

$$
\varepsilon_{i n}(z)=C_{\mu}^{3 / 4} k^{3 / 2} /(\kappa z)
$$

The RNG $k-\varepsilon$ model with a standard wall function was adopted to solve the 
turbulence. To ensure grid independency, the medium and fine grid arrangements were used with the smallest grid size of $\triangle x=\triangle y=\triangle z=0.1 \mathrm{~m}$ and $0.05 \mathrm{~m}$ at wall surfaces respectively. For the medium and fine grid, the hexahedral meshes of 0.49 and 1.14 million are produced (Fig. A3a). All the other CFD setups are similar to subsection 2.1 .

Figs. A $3 \mathrm{~b}$ and A3c show the vertical profiles $U(z) / U_{\text {ref }}$ along the vertical lines at $x=-0.04 H, x=0.5 H$ for windward single-sided ventilation, and at $x=0.5 H, x=1.04 H$ for leeward single-sided ventilation. Here $U_{\text {ref }}$ is the reference velocity $(10 \mathrm{~m} / \mathrm{s})$. The predicted $U(z) / U_{\text {ref }}$ profiles match wind tunnel data well for regions below and near the roof level. The grid independence study shows little difference between two grid arrangements. These facts confirm the RNG $k-\varepsilon$ model with medium grids (minimum grids of $\triangle x=\triangle y=\triangle z=0.1 \mathrm{~m}$ ) performs well in predicting single-sided ventilation airflows.

\subsection{CFD Validation of pollutant dispersion modelling in 2D street canyons}

Meroney et al. (1996) conducted wind tunnel experiments of pollutant dispersion in 2D street canyons with a perpendicular wind to its street axis (Fig. A4 in Appendix). There were 28 parallel $2 \mathrm{D}$ street canyons (uniform building height $H=W=B=60 \mathrm{~mm}$ ) with 20 street canyons upstream to the target street canyon and 8 downstream. A steady line tracer gas (ethane) source exists in the target street. In CFD simulations, the same model geometry and boundary conditions with wind tunnel experiments were adopted (Fig. A4). The total grid number was 372.889. No slip wall boundary condition was set at wall surfaces. The normalized concentration is defined as $K=\bar{c}$

$U H L / Q$, where $\bar{c}$ is the measured tracer gas concentration, $L$ is line source length and $Q$ is the source emission rate, $U$ is wind velocity measured in the free stream at $0.50 \mathrm{~m}$ above wind tunnel floor. With $V_{\text {in }}=3 \mathrm{~m} / \mathrm{s}$ at the domain inlet, Fig. A4 shows the CFD validation profiles of $K$ along windward and leeward walls. As expected windward $K$ is much lower than that leeward $K$. Numerical $K$ predicted by the RNG $k-\varepsilon$ model agree with wind tunnel data generally well. 


\section{Results and discussion}

\subsection{Effects of aspect ratio, viaduct and noise barriers on flow and dispersion}

Figs. 2 and 3 display streamline, velocity and $\mathrm{CO}$ concentration in the lateral centre plane in some example test cases. Note that for cases with a viaduct, two situations are included, i.e. with only a single elevated CO source or two CO sources at the viaduct-level and ground-level. Obviously, as $W / H=1$ or 2 , the single clockwise main vortex exists with different locations of vortex centre (Fig. 2), and the leeward-side concentration is always much higher than that on the windward-side (Fig. 3 ). Wider streets $(W=2 H=48 \mathrm{~m}$ ) always experience much lower concentrations than narrower streets with $W=H=24 \mathrm{~m}$, no matter with or without a viaduct (Fig. 3). These findings are similar to those in the literature representing different types of flow regions in the street canyon (e.g. Oke, 1988; Meroney et al., 1996; Xie et al., 2006; Allegrini et al., 2014). In addition, the existence of a viaduct slightly elevates or changes the vortex centre (Fig. 2). Since the single CO source is elevated onto the viaduct, the high-pollution region is raised onto the viaduct level (Fig. 3), moreover, $\mathrm{CO}$ concentration in the leeward-side building becomes much lower than that without a viaduct (Fig. 3) because the elevated viaduct reduce the distance of source to street roof level and improve pollutant dispersion out of the street canyon. In principle, it can be regarded as an introduction of a new horizontal surface with the street canyon, therefore the street canyon is divided into two parts vertically. Therefore, the effective aspect ratio is reduced by the elevated viaduct surface. If noise barriers are fixed on viaducts (Case Vb2[W/H]), due to their shelter effect the velocity above viaducts and between barriers is relatively small (Fig 2), a much higher pollutant concentration is expected between the barriers (Fig. 3), Therefore, a higher exposure to drivers in the vehicles on the urban viaduct can be envisaged, but noise barriers seem not to raise $\mathrm{CO}$ concentration in the near-road buildings.

In cases with a viaduct, we also consider two CO sources (ground-level and viaduct-level), assuming the total realistic pollutant emission rate doubles due to the increase of the traffic capacity. As two examples, Fig. 3 also shows CO concentration 
in the lateral centre plane in Case $\mathrm{Vb} 2[1]$ and $\mathrm{Vb} 2[2]$ with the viaduct and two $\mathrm{CO}$ sources $(W / H=1$ or 2$)$. Obviously, in contrast to those with the single elevated source, even the flow is the same, $\mathrm{CO}$ concentration with two sources is much higher. For a street of $W=H=24 \mathrm{~m}$, the leeward-side rooms at the first and second floors are polluted more seriously than the upper floors. For a wider street $(W=2 H=48 \mathrm{~m})$, vertical gradient of CO concentration for rooms in both windward and leeward sides are small.

\subsection{Effects of aspect ratios, viaduct and noise barriers on daily $C O$ exposure}

\section{Vertical profiles of indoor daily $\mathrm{CO}$ exposure at various heights}

Fig. 4 displays the spatially-averaged indoor daily $\mathrm{CO}$ exposure at each floor of near-road buildings with a single ground-level or viaduct-level CO source. Obviously, wider streets $(W / H=1,1.5,2)$ are prone to smaller $\mathrm{CO}$ exposure for each floor, and leeward-side $\mathrm{CO}$ exposures are always greater than windward-side. More importantly, in contrast to Case $\mathrm{Nv}[\mathrm{W} / H]$ without a viaduct (single ground-level source), cases with a viaduct (single viaduct-level source) always attain smaller leeward-side CO exposure but greater windward-side $\mathrm{CO}$ exposure. For cases with a viaduct, Figs. 4 also compares daily $\mathrm{CO}$ exposure in each floor with single source and with two sources. As $W / H=1,1.5$ and 2, two sources obviously produce much greater daily $\mathrm{CO}$ exposure than single source. Moreover noise barriers only slightly affect daily $\mathrm{CO}$ exposure in near-road buildings. $\mathrm{CO}$ exposure decreases slightly towards upper levels..

\section{Total CO exposure $\left(E_{t}\right)$, for indoors $\left(E_{\mathrm{indoor}}\right)$ and at pedestrian level $\left(E_{\mathrm{ped}}\right)$}

Figs. 5-6 and Table 2 display the average daily $\mathrm{CO}$ exposure in the entire near-road buildings $\left(E_{\text {indoor }}\right)$ and that at the pedestrian level $\left(E_{\text {ped }}\right)$ with one source or two sources as well as their ratios in all test cases.

When only one single $\mathrm{CO}$ source is presented on the elevated viaduct, viaduct settings $(\mathrm{V}, \mathrm{Vb} 1, \mathrm{Vb} 2)$ could attain much smaller $\mathrm{CO}$ exposure both indoors and at pedestrian level than those without a viaduct (Nv), accounting for only $60-75 \%$ of total CO exposure for non-viaduct cases (Table 2). Meanwhile, the ratios of 
leeward-side $\mathrm{CO}$ exposure to windward-side $\left(E_{\text {leeward1 }} / E_{\text {windward1 }}\right)$ are 3.34-3.96 in cases without viaduct, but this ratio in cases with viaducts are only 1.16-1.23 (Table 2). These results confirm that, viaduct settings significantly weaken the exposure ratio $E_{\text {leeward1 }} / E_{\text {windward1 }}$ by reducing leeward-side $\mathrm{CO}$ exposure and raising windward-side $\mathrm{CO}$ exposure. Furthermore, Figs. 5 and 6 also show that widening the street (from $W / H=1$ to 2 ) could potentially reduce total daily $\mathrm{CO}$ exposure for all the cases. Finally, noise barriers ( $\mathrm{Vb} 1, \mathrm{Vb} 2)$ do not have significant impact on the daily $\mathrm{CO}$ exposure for the viaduct settings (Figs. 5-6), however, it should be noted that they may increase the in-vehicle exposure on the viaduct although it is not the focus of current study.

When there exist two CO sources (both at the pedestrian and viaduct levels), the total $\mathrm{CO}$ exposure $\left(E_{\mathrm{t} 2}=E_{\mathrm{indoor} 2}+E_{\mathrm{ped} 2}\right)$ can be 2.67-3.33 times as great as those with a single CO source $\left(E_{t 1}=E_{\text {indoor1 }}+E_{\text {ped1 }}\right)$ (Fig. 5 and Table 2), and $E_{\text {leeward2 }} / E_{\text {windward2 with }}$ two sources are 2.40 to 3.52 , which is much greater than $E_{\text {leeward1 }} / E_{\text {windward1 }}(1.16$ to 1.23 ) with a single source (Table 2 ). Irrespective of the number of $\mathrm{CO}$ sources, $E_{\text {indoors }}$ are always 6-9 times of $E_{\mathrm{ped}}$ since people spend much shorter time outdoors (at pedestrian level) than indoors (Fig. 5 and Table 2), highlighting the importance of necessity to include indoor exposure to outdoor origins into the traditional epidemiological pollution exposure study.

\subsection{Effects of aspect ratios, viaduct and noise barriers on intake fraction}

Personal intake fraction $\left(P_{-} I F\right)$ are depicted in Fig. 7 and Table2. For all cases investigated, wider streets (or greater $W / H$ ) experience smaller $P \_I F$.

For cases with the single CO source, the values of $P \_I F$ for non-viaduct cases $(\mathrm{Nv}[W / H])$ are 5.21, 3.06 and $2.23 \mathrm{ppm}$ respectively for $W / H=1,1.5,2$. With viaduct setting and a single elevated CO source $(\mathrm{V}[W / H]), P \_I F$ exhibits smaller values (1.46-3.59 ppm). Moreover, the introduction of noise barrier on the viaduct ( $\mathrm{Vb} 1[W / H]$ and $\mathrm{Vb} 2[W / H])$ show similar $P_{-} I F$ as those without noise barrier $(\mathrm{V}[W / H])$ but are still much smaller than non-viaduct cases $(\mathrm{Nv}[W / H])$.

If two CO sources are introduced in cases with viaduct settings, personal intake fraction $\left(P_{-} I F_{2}\right)$ is obviously greater than the one with a single source $\left(P_{-} I F_{l}\right)$. The 
ratio of $P_{-} I F_{2} / P_{-} I F_{1}$ ranges from 1.34 to 1.66 , which is only half of the CO exposure

ratio $E_{t 2} / E_{t 1}(2.67$ to 3.33$)$. It is reasonable that the intake fraction is an index

normalized by the total pollutant emission rate whereas $\mathrm{CO}$ exposure is not. No matter one source or two sources, noise barriers ( $\mathrm{Vb} 1[W / H], \mathrm{Vb} 2[W / H])$ seem to have little influence on personal intake fraction.

Finally, if it is assumed that 10 persons are living on each floor of the near-road buildings ( 8 floors, 160 persons), the total intake fraction (Table 2) ranges from 230 ppm to $834 \mathrm{ppm}$ in cases with one source and $387 \mathrm{ppm}$ to $913 \mathrm{ppm}$ for cases with two sources. Our results are comparable to those in a street canyon $(H / W=1.5)$ in the central Athens urban area, Greece (371 ppm) (Habilomatis and Chaloulakou, 2015), but much smaller than that in a typical deep street canyon in midtown Manhattan, New York (3,000 ppm), where a much larger population density was studied (Zhou and Levy, 2008). In this regard, the newly developed index of personal intake fraction among different design strategies. show strong merits of independency of population density and emission rate, and is mainly decided by urban layouts and meteorological conditions, allowing comparison

\subsection{Limitations}

It should be noted that we assumed the near-road buildings are residential-type. The current $\mathrm{CO}$ exposure evaluation possibly changes if different assumptions are adopted, for example the near-road buildings are office-type or mixture of office/residential types, or age subgroups and time patterns differ from Figs. 1b-1c. Although further investigations are still required to provide practical guidelines, this paper is one of the first attempts to quantify the significant source-exposure relationship influenced by the key factors of street layouts, configurations of viaducts/noise barriers. The findings can provide meaningful reference for decision makers and urban planners in formulating appropriate street and viaduct design policies to reduce near-road pollutant exposures. The methodologies adopted are confirmed promising and effective to assess the effects of various urban layouts and meteorological conditions on vehicular human exposure in more kinds of 
realistic/idealized urban models, for sustainable urban design purpose.

Our simulations mainly emphasize the cases with all windows open, allowing most potential of indoor-outdoor air exchange, however, in the reality, the windows may be closed or partly closed due to various reasons such as protection from the outside noise and cold air in the winter, using air conditioners in hot summer and desirable human behaviour among the others. The status of the windows may have significant impact on the penetration of outdoor pollutions and therefore alter the magnitude of indoor exposure to outdoor pollutants, for example, previous studies have found the installation of air-conditioners and close of the windows in winter is linked to the reduced risk to the mortality due to exposure to outdoor pollution (Chen et al., 2012a,b). Future work has been planned to consider such issue by integrating CFD and multi-zone building airflow modelling.

\section{Conclusions}

The present work is devoted to investigating the relationship of urban design and $\mathrm{CO}$ exposure both indoors and at pedestrian level to urban vehicular $\mathrm{CO}$ emissions, addressing the gap between the urban planning and pollution exposure field. Validated by wind tunnel data, CFD simulations are preformed to assess the effect of widening street ( $W / H=1,1.5,2$ as the road-side building height $H=24 \mathrm{~m})$ and introducing viaducts and noise barriers on pollutant dispersion and vehicular human exposure when realistic $\mathrm{CO}$ sources are defined. As a novelty, both personal intake fraction $\left(P_{-} I F\right)$ and daily $\mathrm{CO}$ exposure $\left(E_{\mathrm{t}}\right)$ are used to quantify vehicular pollutant exposure. $P \_I F$ is a dimensionless index for overall exposure which is independent of the pollutant emission rate, but $\mathrm{CO}$ exposure depends on realistic pollutant emission rates and can show spatial distributions of exposure at various floor heights in near-road buildings.

The simulation results show that wider streets experience smaller $P \_I F$ and CO exposure, and leeward-side buildings always attain less vehicular pollutant exposure than windward-side. In contrast to cases without a viaduct $\left(P_{-} I F=5.21-2.23 \mathrm{ppm}\right.$ as $W / H=1,1.5,2)$, the viaduct can lead to smaller $P_{-} I F(3.25-1.46 \mathrm{ppm})$ if the single 
pollutant source is elevated onto the viaduct level. Noise barriers on viaducts can significantly raise $\mathrm{CO}$ concentration above the viaduct and between the barriers, but slightly reduce pollutant exposure in near-road buildings. Assuming that 10 persons are living on each floor (8 floors, totalling 160 persons in two near-road buildings), the total intake fractions range from 230-913 ppm, which are the same order with that (371 ppm) in a street canyon $(H / W=1.5)$ of the central Athens urban area in Greece (Habilomatis and Chaloulakou, 2015), but are much smaller than that (3,000 ppm) in a deep street canyon in midtown Manhattan, New York, with a large population density (Zhou and Levy, 2008). Because people spend most of their time indoors, pollutant exposure in near-road buildings can be 5-8 times greater than that at the pedestrian level of street canyons. Finally, the introduction of a viaduct tends to reduce pollutant exposure in leeward-side buildings but slightly raises that of windward-side. If there are two CO sources (ground-level, viaduct-level) in cases with a viaduct, overall $\mathrm{CO}$ exposure is much greater (2.80-3.33 times) than cases with a single elevated source above a viaduct. The ratios of leeward-side and windward-side exposure with two CO sources (2.40-3.52) are much greater than those with a single CO source (1.16-1.23).

\section{Conflict of interest}

\section{Acknowledgements}

This study was financially supported by the National Natural Science Foundation of China (No 51478486) and the National Science Fund for Distinguished Young Scholars (No 41425020) as well as the Fundamental Research Funds for the Central Universities (No 161gzd01).

\section{References}

Allan, M., Richardson, G.M., Jones-Otazo, H., 2008. Probability density functions describing 24-hour inhalation rates for use in human health risk assessments: an 
update and comparison. Hum. Ecol. Risk. Assess. 14, 372-391.

Allegrini, J., Dorer, V., Carmeliet, J., 2014. Buoyant flows in street canyons: Validation of CFD simulations with wind tunnel measurements. Build. Environ. 72, 63-74.

Bennett, D., Margni, M., McKone, T., Jolliet, O., 2002. Intake fraction for multimedia pollutants: a tool for life cycle analysis and comparative risk assessment. Risk. Assess. 22, 905-918.

Blocken, B., 2015. Computational fluid dynamics for urban physics: importance, scales, possibilities, limitations and ten tips and tricks towards accurate and reliable simulations. Build. Environ. 91, 219-245.

Buccolieri, R., Sandberg, M., Di Sabatino, S., 2010. City breathability and its link to pollutant concentration distribution within urban-like geometries. Atmos. Environ. 44, 1894-1903.

Buccolieri, R., Salim, S.M., Leo, L.S., Di Sabatino, S., Chan, A., Ielpo, P., de Gennaro, G., Gromke, C., 2011. Analysis of local scale tree-atmosphere interaction on pollutant concentration in idealized street canyons and application to a real urban junction. Atmos. Environ. 45, 1702-1713.

Cai, X.M., 2012. Effects of differential wall heating in street canyons on dispersion and ventilation characteristics of a passive scalar. Atmos. Environ. 51, 268-277.

Chang, C.H., Meroney, R.N., 2003. Concentration and flow distributions in urban street canyons: wind tunnel and computational data. J. Wind. Eng. Ind. Aerodn. $91,1141-1154$.

Chau, C.K., Tu, E.Y., Chan, D.W.T., Burnett, C.J., 2002. Estimating the total exposure to air pollutants for different population age groups in Hong Kong. Environ. Inter. 27, 617-630.

Chen, C., Zhao, B., Weschler, C. 2012a. Assessing the Influence of Indoor Exposure to "Outdoor Ozone" on the Relationship between Ozone and Short-term Mortality in US Communities. Environ. Health. Persp. 120,235-240

Chen, C., Zhao, B., Weschler, C. 2012b. Indoor Exposure to "Outdoor PM10": Assessing Its Influence on the Relationship Between PM10 and Short-term 
Mortality in US Cities. Epidemiol., 23,270-278

Chen, C., Zhao, B., Zhou, W.T., Jiang, X.Y., Tan, Z.C., 2012c. A methodology for predicting particle penetration factor through cracks of windows and doors for actual engineering application. Build. Environ. 47, 339-348.

Cui, P.Y., Li, Z. , Tao, W.Q., 2016. Wind-tunnel measurements for thermal effects on the air flow and pollutant dispersion through different scale urban areas. Build. Environ. 97, 137-151.

Dallman, A., Magnusson, S., Britter, R., Norford, L., Entekhabi, D., Fernando, H. J. S., 2014. Conditions for thermal circulation in urban street canyons. Build. Environ, 80(10),184-191.

Di Sabatino, S., Buccolieri, R., Pulvirenti, B., Bitter, R., 2007. Simulations of pollutant dispersion within idealised urban-type geometries with CFD and integral models, Atmos. Environ. 41, 8316-8329.

Di Sabatino, S., Buccolieri, R. Salizzoni, P., 2013. Recent advancements in numerical modelling of flow and dispersion in urban areas: a short review. Int. J. Environ. Pollut. 52, 172-191.

Fenger, J., 1999. Urban air quality. Atmos. Environ. 33, 4877-4900.

Fernando, H.J.S., Zajic, D., Di Sabatino, S., Dimitrova, R., Hedquist, B., 2010. Flow, turbulence, and pollutant dispersion in urban atmospheres. Phys. Fluids. 22, $1-20$.

FLUENT V6.3, 2006 http://fluent.com.

Gao N.P., Niu J.L., Perino M., Heiselberg P., 2008. The airborne transmission of infection between flats in high-rise residential buildings: Tracer gas simulation. Build. Environ. 43, 1805-1817.

Greco, S.L., Wilson, A.M., Spengler, J.D., Levy, J.I., 2007. Spatial patterns of mobile source particulate matter emissions-to-exposure relationships across the United States. Atmos. Environ. 41, 1011-1025.

Gromke, C., Blocken, B., 2015. Influence of avenue-trees on air quality at the urban neighborhood scale. Part I: Quality assurance studies and turbulent Schmidt number analysis for RANS CFD simulations. Environ. Pollut. 196, 214- 223. 
Gromke, C., Blocken, B., 2015. Influence of avenue-trees on air quality at the urban neighborhood scale. Part II: Traffic pollutant concentrations at pedestrian level. Environmental Pollution 196, 176-184.

Gu, Z.L., Zhang, Y.W., Cheng, Y., Lee, S.C., 2011. Effect of uneven building layout on airflow and pollutant dispersion in non-uniform street canyons. Build. Environ.46, 2657-2665.

Habilomatis, G., Chaloulakou, A., 2015. A CFD modelling study in an urban street canyon for ultrafine particles and population exposure: The intake fraction approach, Sci. Total. Environ. 530-531, 227-232.

Hang, J, Li, Y.G., 2011. Age of air and air exchange efficiency in high-rise urban areas. Atmos. Environ. 45(31),5572-5585.

Hang, J., Li, Y.G., Sandberg, M., Buccolieri, R., Di Sabatino, S., 2012. The influence of building height variability on pollutant dispersion and pedestrian ventilation in idealized high-rise urban areas. Build. Environ.56, 346-60.

Hang J., Lin M., Wong D.C., Wang X., Wang B., Buccolieri R., 2016. On the influence of viaduct and ground heating on pollutant dispersion in 2D street canyons and toward single-sided ventilated buildings. Atmos. Pollut. Res., 1-16.

Ho, Y.K., Liu, C.H., Wong, M.S., 2015. Preliminary study of the parameterisation of street-level ventilation in idealised two-dimensional simulations. Build. Environ. $89,345-355$.

Ji, W.J., Zhao, B., 2015. Estimating mortality derived from indoor exposure to particles of outdoor origin. PLOS. ONE. 10, e0124238.

Jiang, Y., Alexander, D., Jenkins, H., Arthur, R., Chen, Q.Y., 2003. Natural ventilation in buildings: measurement in a wind tunnel and numerical simulation with large-eddy simulation. J. Wind. Eng. Ind. Aerodn. 91, 331-353.

Jin, R.Q., Hang, J., Liu, S.S., Wei, J.J., Liu, Y., Xie, J.L., Sandberg, M. 2015. Numerical investigation of wind-driven natural ventilation performance in a multi-storey hospital by coupling indoor and outdoor airflow. Indoor. Built. Environ. 0(0),1-22.

Kalaiarasan, M., Balasubramanian, R., Cheong, K.W.D.., Tham, K.W., 2009. Traffic- 
generated airborne particles in naturally ventilated multi-storey residential buildings of Singapore: Vertical distribution and potential health risks, Build. Environ. 44, 1493-1500.

Kanda, M., 2006. Large-eddy simulations on the effects of surface geometry of building arrays on turbulent organized structures, Boundary-lay. Meteorol. 18, 151-168.

Kumar, P., Ketzel, M., Vardoulakis, S., Pirjola, L., Britter, R., 2011. Dynamics and dispersion modelling of nanoparticles from road traffic in the urban atmospheric environment-A review. J. Aerosol. Sci. 42, 580-603.

Kwak, K.H., Lee, S.H., Seo, J.M., Park, S.B., Baik, J.J., 2016. Relationship between rooftop and on-road concentrations of traffic-related pollutants in a busy street canyon: Ambient wind effects. Environ. Pollut. 208, 185-197.

Lateb, M., Meroney, R.N. , Yataghene, M., Fellouah, H. , Saleh, F., Boufadel, M.C., 2016. On the use of numerical modelling for near-field pollutant dispersion in urban environments - A review. Environ. Pollut. 208, 271-283.

Li, X.X., Liu, C.H., Leung, D.Y.C., Lam, K.M., 2006. Recent progress in CFD modelling of wind field and pollutant transport in street canyons. Atmos. Environ. 40, $5640-5658$.

Li, X.X., Liu, C.H., Leung, D.Y.C., 2009. Numerical investigation of pollutant transport characteristics inside deep urban street canyons. Atmos. Environ. 43(15), 2410-2418.

Li, X.X., Britter, R.E., Norford, L.K., 2015. Transport processes in and above two-dimensional urban street canyons under different stratification conditions: results from numerical simulation. Environ. Fluid. Mech. 15, 399-417.

Lin, M., Hang, J., Li, Y.G., Luo, Z.W., Sandberg, M., 2014. Quantitative ventilation assessments of idealized urban canopy layers with various urban layouts and the same building packing density. Build. Environ.79, 152-167.

Liu, C.H., Ng, C.T., Wong, C.C.C., 2015. A theory of ventilation estimate over hypothetical urban areas. J. Hazard. Mater. 296, 9-16. 
Liu, C.H., Wong, C.C.C., 2014. On the pollutant removal, dispersion, and entrainment over two-dimensional idealized street canyons. Atmos. Res. 135-136,128-142.

Luo, Z.W., Li, Y.G., Nazaroff, W.W., 2010. Intake fraction of nonreactive motor vehicle exhaust in Hong Kong. Atmos. Environ. 44, 1913-1918.

Luo, Z.W., Li, Y.G., 2011. Passive urban ventilation by combined buoyancy-driven slope flow and wall flow: Parametric CFD studies on idealized city models. Atmos. Environ. 45, 5946-5956.

Marshall, J.D., Teoh, S.K., Nazaroff, W.W., 2005. Intake fraction of nonreactive vehicle emissions in US urban areas. Atmos. Environ. 39, 1363-1371.

Meroney, R.N, Pavageau, M., Rafailidis, S., Schatzmann, M., 1996. Study of line source characteristics for 2-D physical modelling of pollutant dispersion in street canyons. J. Wind. Eng. Ind. Aerodn. 62, 37-56.

Meroney, R.N., 2016.Ten questions concerning hybrid computational/physical model simulation of wind flow in the built environment. Build. Environ. 96,12-21.

Nazarian, N., Kleissl, J., 2016. Realistic solar heating in urban areas: Air exchange and street-canyon ventilation. Build. Environ. 95, 75-93.

Nazaroff, W.W., 2008. Inhalation intake fraction of pollutants from episodic indoor emissions. Build. Environ. 43, 269-277.

Ng, W., Chau, C., 2014. A modelling investigation of the impact of street and building configurations on personal air pollutant exposure in isolated deep urban canyons, Sci. Total. Environ. 468-469, 429-448.

Oke, T.R., 1988. Street design and urban canopy layer climate. Energ. Buildings. 11, 103-113.

Pu, Y.C., Yang, C., 2014. Estimating urban roadside emissions with an atmospheric dispersion model based on in-field measurements. Environ. Pollut. 192,300-307.

Quang, T.N., He, C., Morawska, L., Knibbs, L.D., Falk, M., 2012. Vertical particle concentration profiles around urban office buildings. Atmos. Chem. Phys. 12, 5017-5030.

Ramponi, R., Blocken, B., 2012. CFD simulation of cross-ventilation for a generic isolated building: impact of computational parameters. Build. Environ. 53,34-48. 
Ramponi, R., Blocken, B., de Coo, L.B., Janssen, W.D., 2015. CFD simulation of outdoor ventilation of generic urban configurations with different urban densities and equal and unequal street widths. Build. Environ. 92, 152-166.

Snyder, W.H., 1972. Similarity criteria for the application of fluid models to the study of air pollution meteorology. Bound-Lay. Meteorol. 3,113-134.

Takano, Y., Moonen, P., 2013. On the influence of roof shape on flow and dispersion in an urban street canyon. J. Wind. Eng. Ind. Aerodyn. 123, 107-120.

Thaker, P., Gokhale, S., 2016. The impact of traffic-flow patterns on air quality in urban street canyons. Environ. Pollut. 208,161-169.

Tominaga, Y., Stathopoulos, T., 2013. CFD simulation of near-field pollutant dispersion in the urban environment: a review of current modeling techniques. Atmos. Environ. 79, 716-730.

van Hooff, T., Blocken, B. 2010. On the effect of wind direction and urban surroundings on natural ventilation of a large semi-enclosed stadium. Comput. Fluids. 39, 1146-1155.

van Hooff, T., Blocken, B. 2013. CFD evaluation of natural ventilation of indoor environments by the concentration decay method: $\mathrm{CO} 2$ gas dispersion from a semi-enclosed stadium. Build. Environ. 61,1-17.

Vardoulakis, S., Fisher, B.E.A., Pericleous, K., Gonzalez-Flesca, N., 2003. Modelling air quality in street canyons: a review. Atmos. Environ. 37, 155-182.

Wang, X.X., Li, Y.G., 2016. Predicting urban heat island circulation using CFD. Build. Environ. 99, 82-97.

Xia, L., Shao, Y., 2005. Modelling of traffic flow and air pollution emission with application to Hong Kong Island. Environ. Model. Soft. 20,1175-1188.

Xie, X.X., Huang, Z., Wang, J.S., 2006. The impact of urban street layout on local atmospheric environment. Build. Environ. 41,1352-1363.

Yakhot, V., Orszag S.A., 1986. Renormalization group analysis of turbulence. I. Basic theory. J. Sci. Comput. 3-51.

Yang, F., Qian, F., Lau, S.S.Y., 2013. Urban form and density as indicators for summertime outdoor ventilation potential: A case study on high-rise housing in 
Shanghai. Build. Environ. 70, 122-137.

Yang, L.N., Li, Y.G., 2009. City ventilation of Hong Kong at no-wind conditions, Atmos. Environ. 43, 3111-3121.

Yang, X.Y., Li, Y.G., 2015. The impact of building density and building height heterogeneity on average urban albedo and street surface temperature. Build. Environ. 90, 146-156.

Yassin, M.F., 2013. Numerical modelling on air quality in an urban environment with changes of the aspect ratio and wind direction. Environ. Sci. Pollut. R. 20, 3975-3988.

Yoshie, R., Mochida, A., Tominaga, Y., Kataoka, H., Harimoto, K., Nozu, T., Shirasawa, T., 2007. Cooperative project for CFD prediction of pedestrian wind environment in the Architectural Institute of Japan. J. Wind. Eng. Ind. Aerodyn. $95,1551-1578$.

Zhang, Y.W., Gu, Z.L., Cheng, Y., Lee, S.C., 2011. Effect of real-time boundary wind conditions on the air flow and pollutant dispersion in an urban street canyon-Large eddy simulations. Atmos. Environ. 45,3352-3359.

Zhang, Y.W., Gu, Z.L., 2013. Air quality by urban design. Nat. Geosci. 6, 506.

Zhang, Y., Kwok, K. C. S., Liu, X. R., Niu, J. L. 2015. Characteristics of air pollutant dispersion around a high-rise building. Environ. Pollut. 204, 280-288.

Zhong, J., Cai, X., Bloss, W.J., 2015. Modelling the dispersion and transport of reactive pollutants in a deep urban street canyon: Using large-eddy simulation, Environ. Pollut. 200, 42-52.

Zhou, B., Zhao, B., Guo, X.F., Chen, R.J., Kan, H.D., 2013. Investigating the geographical heterogeneity in PM10-mortality associations in the China Air Pollution and Health Effects Study (CAPES): A potential role of indoor exposure to PM10 of outdoor origin. Atmos. Environ. 75, 217-223.

Zhou, Y., Levy, J.I., 2008. The impact of urban street canyons on population exposure to traffic-related primary pollutants. Atmos. Environ. 42,3087-3098. 


\section{Table list}

Table 1. Summary of test cases investigated by CFD simulations.

Table 2. Daily CO exposure, personal intake fraction $\left(P_{-} I F\right)$ and total intake fraction $(I F)$ in Cases $\mathrm{Nv}[W / H], \mathrm{V}[W / H]$ and $\mathrm{Vb} 2[W / H]$.

\section{Figure list}

Fig. 1. CFD domain and model descriptions with or without viaduct.

Fig. 2. Streamline and velocity in the lateral centre plane in Cases $\mathrm{Nv}[1], \mathrm{Nv}[2]$, $\mathrm{Vb} 2[1], \mathrm{Vb} 2[2]$.

Fig. 3. Concentration in the lateral centre plane in Cases $\mathrm{Nv}[1], \mathrm{Nv}[2], \mathrm{V}[1], \mathrm{V}[2]$, Vb2[1], Vb2[2] with the single CO source or two CO sources.

Fig. 4. Indoor daily $\mathrm{CO}$ exposure at different floors in some example cases $\mathrm{Nv}[W / H]$, $\mathrm{V}[W / H]$ and $\mathrm{Vb} 2[W / H]$ with the single pollutant source or with two $\mathrm{CO}$ sources.

Fig. 5. Daily CO exposure of $E_{\text {indoor }}, E_{\text {ped }}$ and their ratios in Cases $\operatorname{Nv}[W / H], \mathrm{V}[W / H]$ and $\mathrm{Vb} 2[W / H]$.

Fig. 6. Overall daily $\mathrm{CO}$ exposure $E_{\mathrm{t}}$ in Cases $\mathrm{Nv}[W / H], \mathrm{V}[W / H]$ and $\mathrm{Vb} 2[W / H]$ with one source or two sources.

\section{Appendix}

Fig. A1. (a) Time patterns/breathing rate for various age subgroups in four microenvironments (Chau et al., 2002; Allan et al., 2008), (b) the 2004 census data of Hong Kong population in Luo et al. (2010).

Fig. A2. (a) Birds' eye view in cases with viaduct, (b) CFD grid arrangements.

Fig. A3. (a) CFD setup in the validation case. Vertical profiles of $U(z) / U_{\text {ref }}$ along vertical lines at the centre section of building model at (b) $x=-0.04 \mathrm{H}$ and $x=0.5 \mathrm{H}$ for windward single-sided ventilation case, (c) $x=1.04 H$ and $x=0.5 H$ for leeward single-sided ventilation case. 